\title{
Habitat Associations in Gastropod Species at East Pacific Rise Hydrothermal Vents $\left(9^{\circ} 50^{\prime} \mathrm{N}\right)$
}

\author{
SUSAN W. MILLS ${ }^{1 *}$, LAUREN S. MULLINEAUX $^{1}$, AND PAUL A. TYLER $^{2}$ \\ ${ }^{1}$ Biology Department, Woods Hole Oceanographic Institution, Woods Hole, Massachusetts 02543; and \\ ${ }^{2}$ National Oceanography Centre, University of Southampton, European Way, \\ Southampton SO 14 3ZH, United Kingdom
}

\begin{abstract}
At deep-sea hydrothermal vents on the East Pacific Rise $\left(9^{\circ} 50^{\prime} \mathrm{N}\right)$, distinct megafaunal assemblages are positioned along strong thermal and chemical gradients. We investigated the distribution of gastropod species to determine whether they associate with specific megafaunal zones and to determine the thermal boundaries of their habitats. Gastropods colonized a series of basalt blocks that were placed into three different zones characterized by vestimentiferan tubeworms, bivalves, and suspension-feeders, respectively. Additional gastropods were collected on selected blocks from higher temperature vestimentiferan habitat and from grab samples of alvinellid polychaetes. On the blocks, gastropod species clustered into a "Cool" group (Clypeosectus delectus, Eulepetopsis vitrea, Gorgoleptis spiralis, and Lepetodrilus ovalis) whose species tended to be most abundant in the suspension-feeder zone, and a "Warm" group (Lepetodrilus cristatus, L. elevatus, L. pustulosus, and Cyathermia naticoides) whose species all were significantly more abundant in the vestimentiferan zone than elsewhere. The temperature ranges of Cool species were generally lower than the ranges of Warm ones, although both groups were present at 3 to $6{ }^{\circ} \mathrm{C}$; also present was Bathymargarites symplector, which clustered with neither group. Three additional species, Rhynchopelta concentrica, Neomphalus fretterae, and Nodopelta rigneae, cooccurred with Warm-group species on selected blocks from hotter habitats. Although a few species were found only in alvinellid collections, most species were not exclusive to a specific megafaunal zone. We propose that species in the Cool and Warm groups occupy specific microhabitats that are present in more than one zone.
\end{abstract}

Received 13 September 2006; accepted 12 February 2007.

* To whom correspondence should be addressed. E-mail: smills@ whoi.edu

\section{Introduction}

A striking feature of hydrothermal vent communities on the East Pacific Rise is the strongly marked faunal zonation associated with vent fluid temperature and chemistry. Areas of vigorous venting (temperatures from $30^{\circ}$ to over $400{ }^{\circ} \mathrm{C}$ and $\mathrm{H}_{2} \mathrm{~S}$ concentrations up to $12 \mathrm{mmol} \mathrm{kg}{ }^{-1}$; von Damm, 1995) are inhabited by alvinellid and other polychaetes. In areas where venting is more diffuse $\left(<30{ }^{\circ} \mathrm{C}, \mathrm{H}_{2} \mathrm{~S}\right.$ concentrations roughly $0.20-0.30 \mathrm{mmol} \mathrm{kg}{ }^{-1}$, moderately acidic pH; Le Bris et al., 2006), vestimentiferan tubeworms, sometimes mixed with mussels, predominate. In areas with even more diluted vent fluids $\left(<7{ }^{\circ} \mathrm{C}, \mathrm{H}_{2} \mathrm{~S}\right.$ roughly $0.15 \mathrm{mmol}$ $\mathrm{kg}^{-1}$, nearly neutral $\mathrm{pH}$ ), the vestimentiferans are replaced by bivalves. Adjacent to the bivalve-dominated zone is an area where temperatures approach ambient $\left(1.8^{\circ} \mathrm{C}\right)$; that area is inhabited by serpulid polychaetes, barnacles, and other suspension feeders.

The habitat associations of these larger macrofauna and megafauna have been well described from submersible observations and monitoring studies (Hessler et al., 1985; Fustec et al., 1987; Shank et al., 1998), but much less information is available on the spatial patterns of smaller macrofauna. These may be extremely numerous but are difficult to observe in the field. Most are too small to identify visually from photographs or video, and they often live within vestimentiferan thickets or under mussel cover. Yet because of their numbers, their contribution to the local ecology is likely significant.

Studies of the smaller macrofauna at deep-sea vents suggest that some species are tightly associated with specific habitat, whereas others are not. On the East Pacific Rise near $13^{\circ} \mathrm{N}$, Jollivet (1996) found a specific set of macrofauna that appeared to be associated with each type of vent microhabitat. In contrast, on the East Pacific Rise near $9^{\circ} \mathrm{N}$, 
several macrofaunal species have been found in more than one type of vent environment (Micheli et al., 2002; Van Dover, 2003; Govenar et al., 2005), and on the Juan de Fuca Ridge many species occur in more than one faunal assemblage and across a range of fluid-flow environments (Sarrazin and Juniper, 1999). However, since each of these studies was conducted and analyzed with different techniques, more study is needed to generalize across taxa or geographic sites.

Macrofauna are difficult to collect because of their small size and often cryptic habitats. Typically they are captured by a vacuum system or within clumps of alvinellid polychaetes, vestimentiferan tubeworms, or bivalves (McLean, 1988; Waren and Bouchet, 1989; Sarrazin et al., 1999; Van Dover, 2003; Govenar et al., 2005). Within these biogenic habitats, thermal and associated chemical gradients may be quite steep, so that it is difficult to characterize the physicochemical environment of an individual macrofaunal inhabitant. For instance, temperatures within a vestimentiferan thicket may range from near-ambient to over $25^{\circ} \mathrm{C}$ (Hessler and Smithey, 1984) and can vary more than $10{ }^{\circ} \mathrm{C}$ at a single point on short $(<1 \mathrm{~h})$ time scales (Le Bris et al., 2006). An alternative system for collecting vent species is to introduce small basalt blocks into the desired habitats and allow them to become colonized (e.g., Mullineaux et al., 2000). Although this system requires patience, the introduced blocks have several advantages. The substratum that the blocks provide is similar to natural basalt but small relative to the spatial extent of each habitat type (the dimensions are similar to typical bottom roughness elements at these vents), can be used in habitats other than those with habitat-forming megafauna, has a consistent and easily quantified surface area, and presents a consistent shape for temperature measurements.

Our main goal in the present study was to characterize the associations of a subset of macrofauna-the gastropodswith the well-established megafaunal assemblages and thermal environments at vents near $9^{\circ} \mathrm{N}$ on the East Pacific Rise. We focused on the gastropods because they are numerous (reaching densities of $7 \times 10^{3}$ individuals $\mathrm{m}^{-2}$; Govenar et al., 2005), diverse, and found in all but the most extreme $\left(\sim 50{ }^{\circ} \mathrm{C}\right.$ and higher) vent habitats. Also, unlike sessile species, they are able to adjust their position in response to changing environmental conditions (Bates et al., 2005), so that their distributions likely reflect present conditions. We quantified species abundances on introduced basalt surfaces to determine whether gastropods occur in discrete species assemblages and to investigate whether these assemblages exhibit habitat zonation patterns similar to those observed in vent megafauna. We also characterized the temperature range inhabited by each species and analyzed how species abundance varied with temperature. Additional qualitative sampling of gastropods from high-temperature habitats was used to extend the scope of the study.
Quantification of these patterns can give us a clearer picture of how species interact with each other and their environment, and may allow us to make predictions about ways in which vent faunas will respond to temporal changes in their environment.

\section{Materials and Methods}

\section{Block colonization experiment}

Most gastropods in this study were collected during a colonization experiment conducted near $9^{\circ} 50^{\prime} \mathrm{N}$ on the East Pacific Rise as part of the National Science Foundation's Larvae at Ridge Vents (LARVe) project. Basalt colonization blocks, roughly $10 \mathrm{~cm}$ on each side, were positioned by the submersible Alvin at three sites along a 2-km section of the ridge (depth $2500 \mathrm{~m}$ ): Biovent, East Wall, and Worm Hole. For the present analyses we used 71 blocks deployed in November 1994 and April 1995 and recovered after intervals of 5 months (Nov 1994 to Apr 1995), 8 months (Apr to Dec 1995), or 13 months (Nov 1994 to Dec 1995).

At each site three replicate blocks were placed within habitats characterized by conspicuous megafaunal associations - the vestimentiferan, bivalve, and suspension-feeder zones (see Mullineaux et al., 2003, for complete experimental design). Worm Hole did not have a mussel-covered zone comparable to those at the other sites; instead, juvenile mussels were sparsely scattered among the serpulids in the suspension-feeder zone. Temperature (maximum value over a period of $\sim 1 \mathrm{~min}$ ) was measured at the base of each block just prior to recovery. This base temperature was consistently as high as, or higher than, elsewhere on the block and provided a consistent point for comparison between blocks.

Blocks were individually recovered by Alvin into separate compartments for transport to the surface. The blocks were examined aboard ship and then preserved in $80 \%$ ethanol. Everything that remained in the collection compartment was sieved over a $63-\mu \mathrm{m}$ screen and preserved separately (designated as sieve samples).

All gastropods, in all size classes, were removed from the blocks in the laboratory and identified to the lowest taxonomic level possible. In addition, all gastropods in the sieve samples that were large enough to be retained on a $1-\mathrm{mm}$ sieve were counted and identified. Juveniles that were too small to identify were eliminated from the analyses.

\section{Complementary block and grab sampling}

Because most of the blocks in the colonization experiment were recovered at temperatures below $12{ }^{\circ} \mathrm{C}$, we also examined all available blocks recovered at higher temperatures (up to $26.3{ }^{\circ} \mathrm{C}$ ) from nearby sites on the same section of the ridge. The three blocks selected from Tica vent had been deployed for 5 months (Dec 1999 to May 2000), and the six from Riftia Field had been in place for 7 months 
(Apr 1999 to Dec 1999). Block recovery and shipboard processing were as detailed above, except that sieve samples were not retained. Both sets of blocks were examined aboard ship for presence of gastropods, and the Tica blocks were sorted again in the laboratory. We undoubtedly failed to detect some species on these blocks because the sieve samples were not examined and the shipboard identifications were not always to the species level. The presence of a species was, however, useful in the context of this study because it helped determine which species occurred at higher temperatures.

No blocks were placed in the higher temperature habitats that support alvinellids (Alvinella pompejana and A. caudata), so gastropods were collected there as bycatch during alvinellid sampling. Alvin's manipulator was used to grab clumps of alvinellids, along with their tubes and associated fauna, and place them into a lidded, insulated sampling box. These collections were made in May 2000 at Q, P, Bio 9, and Alvinellid Pillar vents, all within the region of our block experiments. Gastropod specimens were recovered from the bottom of the box after the larger animals were removed. Individuals retained on a $0.5-\mathrm{mm}$ sieve were sorted under a Wild stereomicroscope on board the ship and either fixed in $10 \%$ seawater formalin and later transferred to $70 \%$ alcohol, or frozen at $-70^{\circ} \mathrm{C}$. Actual counts were made when time permitted; otherwise the abundances were estimated in categories of few $(<10)$, common (10-25), abundant (25$100)$, or very abundant $(>100)$. The use of a $0.5-\mathrm{mm}$ sieve rather than the $1.0-\mathrm{mm}$ sieve used for block samples could potentially elevate abundances of the few species (e.g., Cyathermia naticoides, Eulepetopsis vitrea, and Clypeosectus delectus) that were identifiable at sizes below $1.0 \mathrm{~mm}$. This issue is considered during interpretation of species presence in the bycatch samples.

Because all megafaunal collections during a dive were retrieved into the same sampling box, the alvinellid collections were unavoidably mixed with grab samples of vestimentiferans and other species from lower temperature habitats. Fortunately, many dives did not collect at hightemperature habitats, so a set of grab samples of vestimentiferans, without alvinellids, was available for comparison. The gastropods from these non-alvinellid collections were processed as above and compared to those from the mixed collections to determine whether any gastropod species appeared to be associated exclusively with alvinellids.

\section{Statistical analyses}

Statistical analyses were performed on the most numerous species from the block experiment (i.e., those with more than 25 individuals). Gastropod species abundances were analyzed with nonmetric multidimensional scaling (MDS; Systat 11.0, using default values for ordinary euclidian distance, and Kruskal loss function) to identify species assemblages. A three-way analysis of variance (ANOVA; Systat 11.0), using zone, site, and deployment duration (interval) as factors, was used to compare gastropod abundances between megafaunal zones. The data were logarithmically transformed $(\ln (x+1))$ to approach homogeneity of variance. Blocks from the bivalve zone were excluded from the ANOVA because the zone did not occur at Worm Hole and at East Wall all the 13-month blocks in it were lost. Mean abundances were compared between zones using Tukey's post hoc comparisons.

Gastropod abundances on the subset of the blocks (56) for which recovery temperatures were measured were used to examine the relation between abundance and thermal habitat. For each species, the central temperature range inhabited by $90 \%$ of individuals was determined by eliminating the $5 \%$ of individuals at the uppermost and lowermost temperatures and presenting the range occupied by those remaining. This range was intended to approximate the typical thermal habitat of a population, rather than the upper or lower physiological tolerance of individuals.

\section{Results}

\section{Faunal associations}

Twelve putative species of gastropods were found on the blocks; of these, nine species (Bathymargarites symplector, Clypeosectus delectus, Cyathermia naticoides, Eulepetopsis vitrea, Gorgoleptis spiralis, Lepetodrilus cristatus, L. elevatus, L. ovalis, and L. pustulosus) were common enough to analyze statistically. Eight of these were found at all sites; $L$. cristatus was absent from the Worm Hole blocks. The three rare species were found only in the vestimentiferan zone at Biovent: Gorgoleptis emarginatus and Peltospira delicata on a single block each and Rhynchopelta concentrica on two blocks.

A two-dimensional plot of the nonmetric multidimensional scaling analysis showed species co-occurring in two distinct groups, with one species, B. symplector, as an outlier (Fig. 1). Of those in the first group (L. cristatus, $L$. elevatus, L. pustulosus, and Cyathermia naticoides), all were most abundant in the vestimentiferan zone and decreased in abundance in the bivalve and suspension-feeder zones (Fig. 2). The differences between the vestimentiferan and suspension-feeder zones were significant for all of these (Table 1; $P<0.0125$ with Bonferroni correction for multiple tests), and we refer to them as Warm species. Of those in the second group (Clypeosectus delectus, E. vitrea, G. spiralis, and $L$. ovalis), designated as Cool species, all tended to be most abundant in the suspension-feeder zone (Fig. 2). However, that pattern was significant only for Clypeosectus delectus. Bathymargarites symplector differed from the other species in that it had anomalously high abundances on two blocks in the bivalve zone-one at 


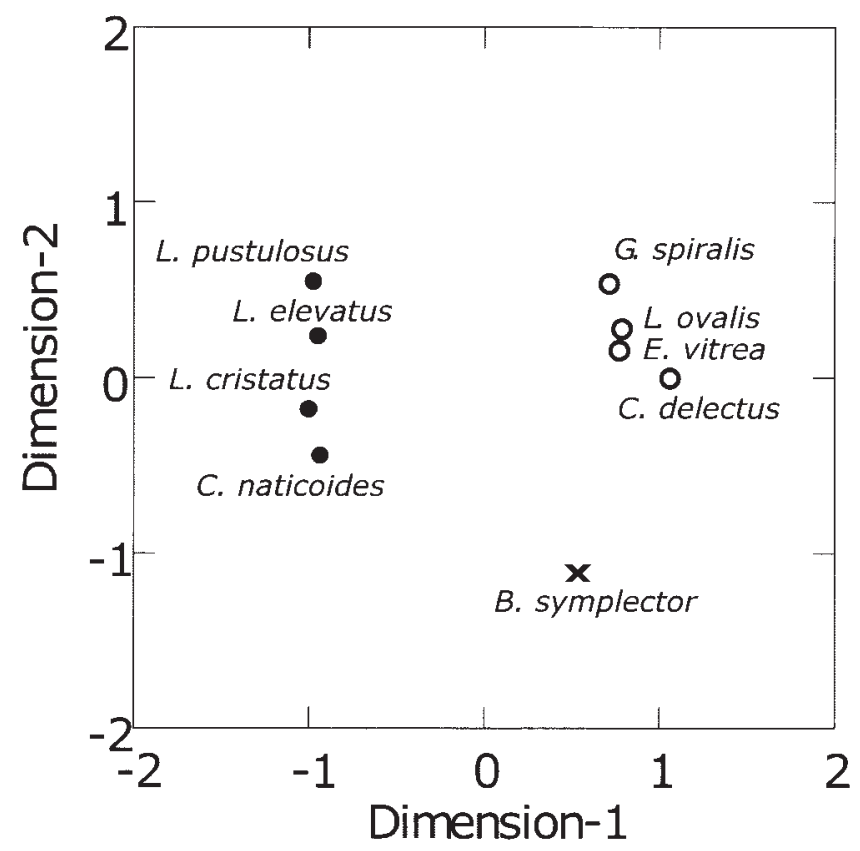

Figure 1. Co-occurrence of gastropod species as displayed by nonmetric multidimensional scaling (MDS; Kruskal Stress $=0.036$ ) of abundances from the quantitative block experiment. Two groups are separated along dimension 1, designated as Warm (closed circles) and Cool (open circles). One species, Bathymargarites symplector $(\times)$, does not cluster with either group.

Biovent and one at East Wall. However, its mean abundance did not differ significantly between zones at either site (one-way ANOVA: $F=0.81$, df $=2, P=0.47$ at Biovent; $F=0.90, \mathrm{df}=2, P=0.42$ at East Wall).

Although we were interested mainly in differences between megafaunal zones, we also detected significant effects of site and interval in the gastropod abundances (Table 1). A site effect was significant for Clypeosectus delectus, G. spiralis, L. cristatus, and L. elevatus. For all of these except $L$. cristatus, there were significantly more individuals at Worm Hole than at the other two sites, which were not significantly different from each other. The site effect for $L$. cristatus was due to its absence from Worm Hole; the other two sites were not significantly different from each other. For this species the zone $\times$ site interaction was also significant. The interval effect for $L$. elevatus was a result of significantly lower abundances on the 5-month blocks than on the 8 -month or 13 -month ones. None of the site or interval effects affect our interpretations of the gastropod zonation patterns.

\section{Thermal habitats}

Fifty-six of the 71 quantitative colonization blocks had temperatures recorded upon recovery. The remainder lacked this information, usually because the Alvin temperature probe malfunctioned. Although the lowest recorded temper- ature for most species was that of ambient seawater $\left(1.8{ }^{\circ} \mathrm{C}\right)$, the $90 \%$ temperature range reveals a distinct difference in the ranges of Warm and Cool species (Fig. 3). For each of our four Cool species, the lower bound of the $90 \%$ range was at ambient temperature $\left(1.8^{\circ} \mathrm{C}\right)$, and none extended higher than $5.9{ }^{\circ} \mathrm{C}$ (G. spiralis). For the Warm species, these ranges all began above $3{ }^{\circ} \mathrm{C}$ and went as high as $11{ }^{\circ} \mathrm{C}$ (Cyathermia naticoides). Bathymargarites symplector fell between the two groups, sharing a lower bound (ambient) with the Cool species, but ranging up to $8.0^{\circ} \mathrm{C}$, nearly as high as L. cristatus. Rhynchopelta concentrica occurred on two blocks at temperatures of 4.6 and $9.8^{\circ} \mathrm{C}$.

Two additional species, Neomphalus fretterae and $\mathrm{No}$ dopelta rigneae, were found on blocks from Riftia Field and Tica vents that had recovery temperatures above $12.0^{\circ} \mathrm{C}$ (Table 2; Fig. 3). The upper recorded temperatures for these species were $25.0{ }^{\circ} \mathrm{C}$ and $26.0{ }^{\circ} \mathrm{C}$, respectively. Rhynchopelta concentrica was also found on all but one of the Tica blocks, at a maximum temperature of $26.3{ }^{\circ} \mathrm{C}$. In most cases, these three species co-occurred with at least one Warm species. No Cool species were found on these blocks. We think they were truly absent, even though individuals that fell off the blocks into the collecting compartments were not examined. In the quantitative block colonization experiment, all Cool species that were detected in the sieved samples were also found directly on the blocks.

Four other species, Peltospira operculata, P. lamellifera, Nodopelta sp., and Pachydermia laevis, that were rare or absent from the blocks were captured as bycatch during collections of alvinellids (Table 3 ). Since all bycatch samples also included species from lower-temperature environments, we divided the samples into two groups: those in which the alvinellids were also sampled and those in which they were not. The absence of these four species in our non-alvinellid samples suggests that they are associated closely with alvinellids. In contrast, all other species, including the Warm and Cool species and $R$. concentrica, were found in approximately equal numbers in both sets of collections. Although it is possible that some of these may co-occur with alvinellids, they do not associate with them exclusively. The presence of Peltospira operculata, P. lamellifera, Nodopelta sp., and Pachydermia laevis in bycatch samples, but not on blocks, is not due to the difference in sieve sizes used ( $0.5 \mathrm{~mm}$ for bycatch, 1.0 for blocks), because these particular species were not among those identifiable to species at sizes below $1.0 \mathrm{~mm}$.

\section{Discussion}

Two distinct gastropod species assemblages, the Cool and Warm groups, were defined in analyses of the quantitative block experiment (Fig. 1). Species in the Warm group were all most abundant in the vestimentiferan zone, but none was restricted to that zone (Fig. 2). Species in the Cool 
Warm Group

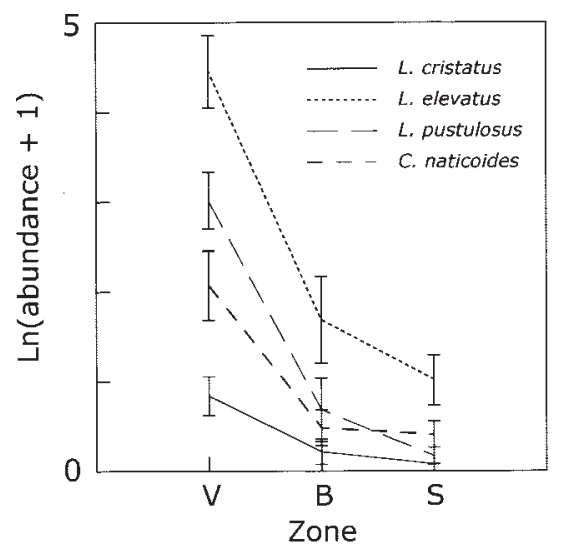

Bathymargarites symplector

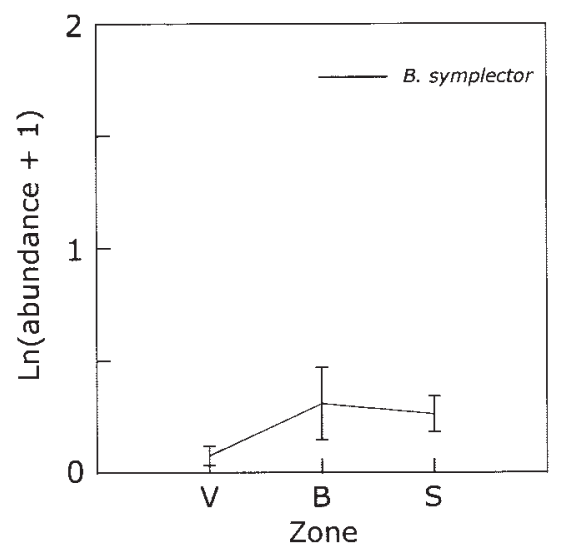

Cool Group

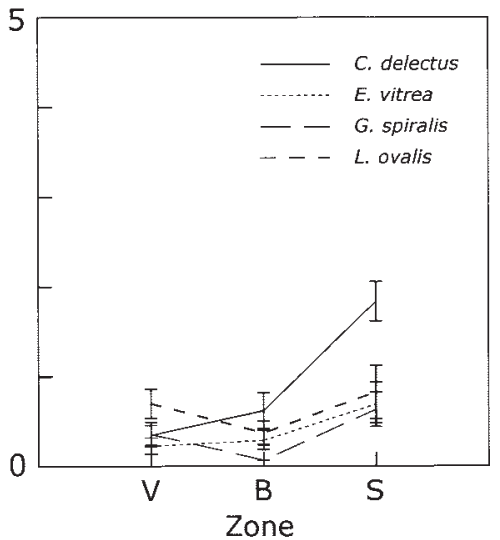

Figure 2. Gastropod abundances in vestimentiferan (V), bivalve (B), and suspension-feeding (S) megafaunal zones. Values are means ( \pm standard error) of $\ln (n+1)$ transformed abundances from quantitative block experiment. Species are divided into Warm and Cool groups on the basis of MDS analysis in Fig. 1 (Bathymargarites symplector was the outlier). Differences between zones as evaluated by ANOVA are displayed in Table 1.

group were generally (but not statistically) more abundant in the suspension-feeder zone than elsewhere. These patterns suggest that although gastropod abundances vary between vestimentiferan, bivalve, and suspension-feeder zones, individual species are not restricted to specific zones.

The Cool and Warm groups occupy different, but overlapping, thermal habitats (Fig. 3). The Cool species were rarely found at temperatures exceeding about $6{ }^{\circ} \mathrm{C}$, whereas the Warm species rarely occurred at temperatures below $3{ }^{\circ} \mathrm{C}$. The upper limits of temperature ranges for the Warm species were not constrained by this data set, because very few of the blocks were recovered at temperatures above $14{ }^{\circ} \mathrm{C}$.

The apparent overlap of some Warm and Cool species in the 3 to $6{ }^{\circ} \mathrm{C}$ range may truly reflect overlapping thermal ranges, or it may be due to imprecision in our temperature measurements. The gastropods on a block do not necessarily experience the thermal environment measured at the block's base; they may be in cooler temperatures, depending on their proximity to the vent fluid source and the small-scale hydrodynamics at the block. Thus, the measured temperatures are, in most cases, only approximations of the thermal environment of the gastropods. Despite this imprecision, it is clear that the Warm group generally inhabits higher temperatures than the Cool group.

Three additional species, Neomphalus fretterae, Rhynchopelta concentrica, and Nodopelta rigneae, co-occur with the Warm group on blocks in the 12 to $26^{\circ} \mathrm{C}$ range (Fig. 3). We include these species in the Warm group, although they are rare or absent in the lower end $\left(3\right.$ to $\left.12{ }^{\circ} \mathrm{C}\right)$ of the group's temperature range. Note that although the species in our assemblages co-occur, they do not necessarily share the same temperature bounds.

We categorize three peltospirid species, Peltospira oper- 
Table 1

Probability (P) values from three-way analysis of variance (ANOVA) of gastropod abundances in the quantitative block experiment

\begin{tabular}{|c|c|c|c|c|c|c|c|c|c|}
\hline \multirow[b]{2}{*}{ Source } & \multicolumn{4}{|c|}{ Warm Group } & \multicolumn{4}{|c|}{ Cool Group } & \multirow{2}{*}{$\begin{array}{c}\text { Other } \\
\begin{array}{c}\text { Bathymargarites } \\
\text { symplector }\end{array}\end{array}$} \\
\hline & $\begin{array}{l}\text { Cyathermia } \\
\text { naticoides }\end{array}$ & $\begin{array}{l}\text { Lepetodrilus } \\
\text { cristatus }\end{array}$ & $\begin{array}{l}\text { Lepetodrilus } \\
\text { elevatus }\end{array}$ & $\begin{array}{l}\text { Lepetodrilus } \\
\text { pustulosus }\end{array}$ & $\begin{array}{c}\text { Clypeosectus } \\
\text { delectus }\end{array}$ & $\begin{array}{l}\text { Eulepetopsis } \\
\text { vitrea }\end{array}$ & $\begin{array}{l}\text { Gorgoleptis } \\
\text { spiralis }\end{array}$ & $\begin{array}{c}\text { Lepetodrilus } \\
\text { ovalis }\end{array}$ & \\
\hline Zone (Z) & $0.001^{*}$ & $<0.001 *$ & $<0.001 *$ & $<0.001 *$ & $<0.001 *$ & 0.056 & 0.176 & 0.732 & 0.082 \\
\hline Site $(\mathrm{S})$ & 0.998 & $0.007 *$ & $<0.001 *$ & 0.447 & $<0.001 *$ & 0.061 & $0.006 *$ & 0.011 & 0.968 \\
\hline Interval (I) & 0.689 & 0.075 & $0.003 *$ & 0.632 & 0.048 & 0.155 & 0.413 & 0.114 & 0.261 \\
\hline $\mathrm{Z} \times \mathrm{S}$ & 0.691 & $0.007 *$ & 0.478 & 0.849 & 0.064 & 0.013 & 0.001 & 0.018 & 0.485 \\
\hline$I \times S$ & 0.733 & 0.266 & 0.789 & 0.616 & 0.179 & 0.794 & 0.328 & 0.985 & 0.606 \\
\hline $\mathrm{I} \times \mathrm{Z}$ & 0.681 & 0.075 & 0.799 & 0.980 & 0.779 & 0.983 & 0.455 & 0.541 & 0.897 \\
\hline $\mathrm{I} \times \mathrm{Z} \times \mathrm{S}$ & 0.817 & 0.266 & 0.117 & 0.484 & 0.452 & 0.300 & 0.471 & 0.672 & 0.349 \\
\hline
\end{tabular}

Zones $(\mathrm{Z})$ were vestimentiferan and suspension-feeder ( $\mathrm{df}=1$; bivalve zone was excluded because of missing data); Sites (S) were Biovent, East Wall, and Worm Hole $(\mathrm{df}=2)$; and Intervals $(\mathrm{I})$ were 5,8 , and 13 months $(\mathrm{df}=2)$. Abundances were $\ln (\mathrm{n}+1)$ transformed. Values that were significant at $P<$ 0.05 (or $P<0.0125$ for Warm and Cool groups that required Bonferroni correction for multiple tests) are marked with an *.

culata, P. lamellifera, Nodopelta sp., and one neomphalid, Pachydermia laevis, that were found only in alvinellid collections into an "Alvinellid" group (Fig. 3). Temperatures were not measured for these specimens, but they likely inhabit at least part of the temperature range tolerated by alvinellids. The temperature limits of alvinellids are not

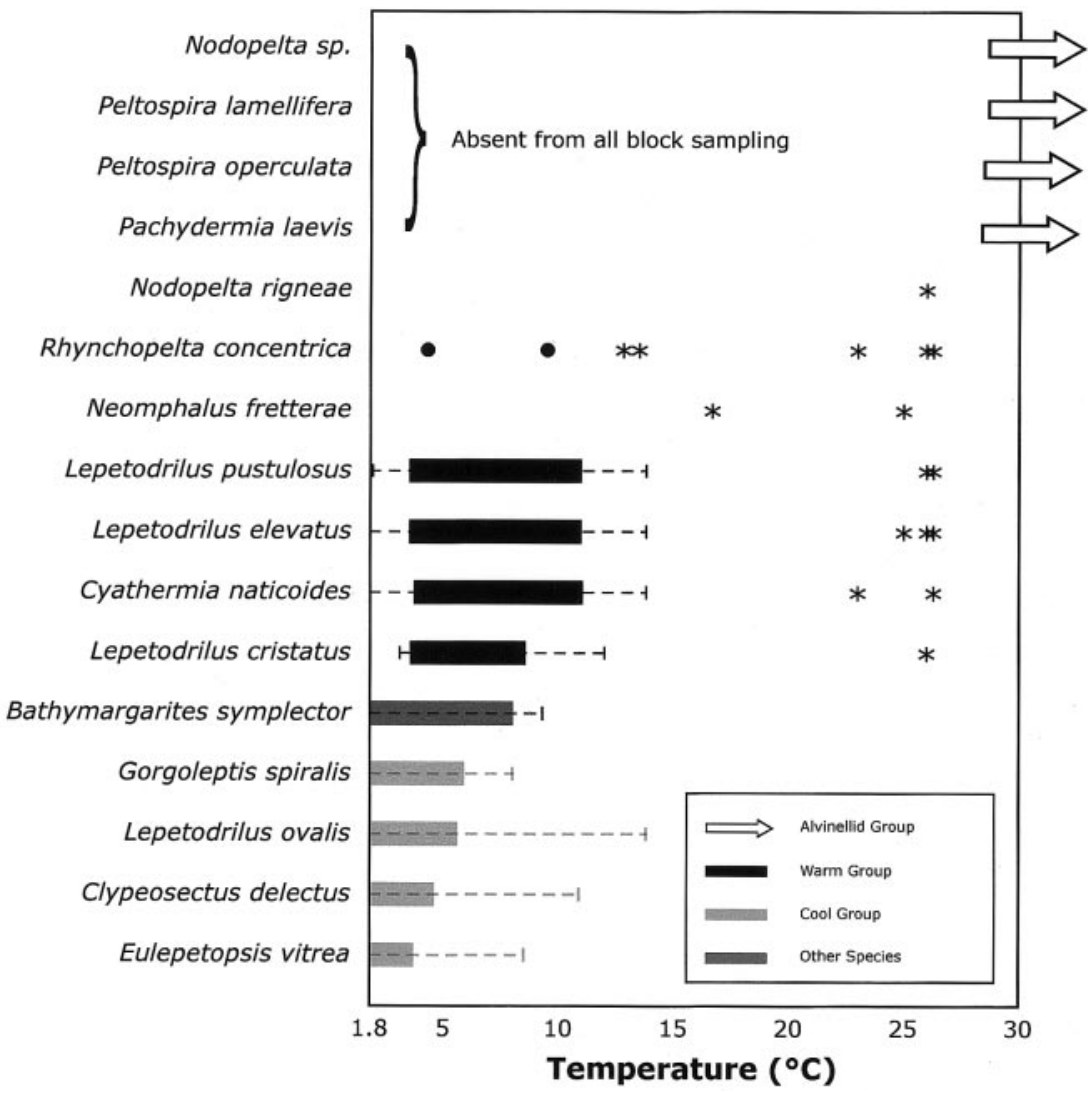

Figure 3. Temperature ranges for gastropod species in diffuse flow in quantitative block experiment and complementary sampling. Solid bars indicate the central temperature range of $90 \%$ of individuals in the quantitative experiment; dashed lines extend to the minimum and maximum temperature recorded for any individual; and circles indicate presence of rare species on individual blocks in that experiment. Asterisks mark presence on blocks in the complementary sampling. Unfilled arrows show estimated temperature range of the Alvinellid group. 
Table 2

Abundance (number of individuals) or presence $(+)$ of gastropod species on individual blocks recovered at temperatures $\left({ }^{\circ} \mathrm{C}\right)>12{ }^{\circ} \mathrm{C}$ from complementary sampling at Tica and Riftia Field

\begin{tabular}{|c|c|c|c|c|c|c|c|c|c|}
\hline \multirow[b]{2}{*}{ Species } & \multicolumn{3}{|c|}{ Riftia Field } & \multicolumn{6}{|c|}{ Tica } \\
\hline & 25.0 & 25.0 & 16.7 & 26.3 & 26.0 & 23.0 & 18.0 & 13.5 & 12.8 \\
\hline Nodopelta rigneae & & & & & 1 & & & & \\
\hline Neomphalus fretterae & & 1 & 1 & & & & & & \\
\hline Rhynchopelta concentrica & & & & 1 & 12 & 7 & & + & + \\
\hline Cyathermia naticoides & & & & 8 & & 19 & & & \\
\hline Lepetodrilus cristatus & & & & & 1 & & & & + \\
\hline Lepetodrilus elevatus & + & & + & 15 & 30 & 28 & & + & + \\
\hline Lepetodrilus pustulosus & & & & 2 & 5 & 13 & & & \\
\hline
\end{tabular}

well defined because of the difficulty of measuring conditions inside their tubes (e.g., Chevaldonné et al., 2000), but the absence of Alvinellid group species in the diffuse flows of up to about $25^{\circ} \mathrm{C}$ that support vestimentiferan colonies suggests an association with higher temperatures or other environmental factors rarely found outside the alvinellid zone. This observed association between peltospirids and alvinellid habitat is consistent with prior collections for taxonomic studies (e.g., McLean, 1989; Warén and Bouchet, 1989, 1993), although specimens of Peltospira and Nodopelta are occasionally found in vestimentiferan clumps or mussel beds (Van Dover, 2003; Govenar et al., 2005) and may be exploiting microhabitats there with atypically high concentrations of vent fluid. In contrast, Pachydermia laevis has been reported consistently from collections of tubeworms and bivalves as well as alvinellids (Warén and Bouchet, 1989, 1993), and likely has broader habitat associations than the peltospirids. Our collections were not sufficiently partitioned to determine whether any of our Warm species also occurred with alvinellids. However, preliminary analyses of colonization experiments in alvinellid habitat near $9^{\circ}$ and $13^{\circ} \mathrm{N}$ on the East Pacific Rise indicate that Lepetodrilus elevatus, L. cristatus, and L. pustulosus all occur in association with Alvinellid group species (M. Zbinden, F. Pradillon, and F. Gaill, Centre Nationale de la Recherche Scientifique, unpubl. data).

Although many of the gastropod species in our samples clustered into discrete assemblages, most of the groups were not exclusive. A few Warm individuals occasionally occurred on blocks dominated by the Cool group, and vice versa. Furthermore, most of the Warm and Cool species were associated with more than one macrofaunal zone. Our results are consistent with prior studies from this region reporting that several Warm species (L. elevatus, Cyathermia naticoides, $R$. concentrica, and L. pustulosus) dominated the gastropod fauna in vestimentiferan clumps (Govenar et al., 2005), but were also occasionally found in mussel beds (Van Dover, 2003). Similarly, Cool species (G. spiralis, L. ovalis, Clypeosectus delectus, and E. vitrea) were among the most abundant gastropods in mussel beds but also, with the exception of Clypeosectus delectus, occurred occasionally in vestimentiferan clumps. At least two of the Alvinellid group species (Peltospira operculata and Pachydermia laevis) have been reported from vestimentiferan clumps (Govenar et al., 2005) or mussel collections (Van Dover, 2003) at nearby sites. We suspect that species within an assemblage are functionally similar, in the sense that they exploit the same resources or are subject to the same predators. The "anomalous" gastropods may be occupying microscale ( $\mathrm{mm}$ to $\mathrm{cm}$ ) habitats that differ distinctly from the general surrounding physicochemical environment. A few species such as the Warm-group lepetodrilids (L. elevatus, $L$. pustulosus, $L$. cristatus) appear to have very wide habitat associations, similar to that observed for L. fucensis at Juan de Fuca vents (Sarrazin and Juniper, 1999).

Segregation of gastropod species has been observed in the field on scales of a few centimeters. For example, vertical zonation has been observed within Riftia pachyptila thickets, in which individuals of Cyathermia naticoides cluster at the bases of the vestimentiferans and those of $L$. elevatus graze higher up the tubes (P. Tyler, pers. obs.). Neomphalus fretterae has been observed in cracks lining diffuse flow outlets (Grassle, 1986), as if it requires more direct exposure to vent fluids or possibly finds a refuge from predation there.

One possible explanation for environmental partitioning by species is that each has a preferred habitat and migrates into it. The individual may be responding to temperature per se, as shown by the shipboard temperature-gradient experiments in Bates et al. (2005), to a chemical species (Luther et al., 2001; Le Bris et al., 2006), or perhaps to a microbial flora. Intertidal limpets have been shown to use chemoreception to return to their home site after foraging and are able to follow mucous trails of conspecifics (Croll, 1983). Alternatively, a gastropod may occupy a particular space because it has a refuge from potential predators or competitors (Micheli et al., 2002; Mullineaux et al., 2003). For example, we know that the vent fish Thermarces cerberus feeds extensively and possibly selectively on L. elevatus (Sancho et al., 2005); this predation may 


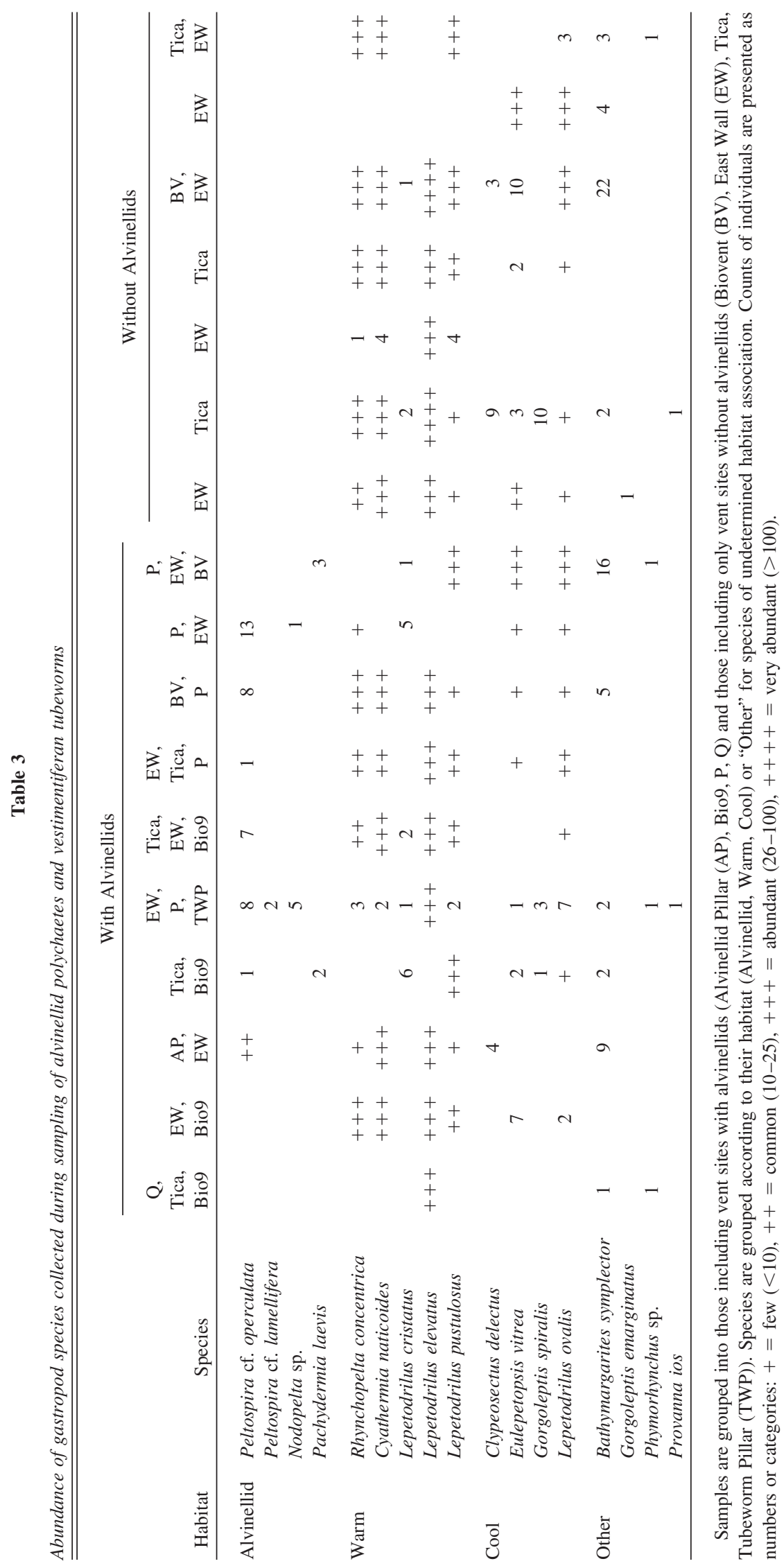


reduce abundances of L. elevatus where it is accessible to the fish and allow other species, including gastropods, to become established. We expect that all these factors-physical, chemical and biological-probably affect gastropod species distributions to some extent. Phylogenetic constraints on physiological adaptations may restrict the habitats available to certain gastropod species. Members of the family Peltospiridae are characteristic of the alvinellid zone and, apart from a single species (Rhynchopelta concentrica), are not generally found in cooler areas at $9^{\circ} \mathrm{N}$. Lee (2003) found that Depressigyra globulus, a peltospirid, had a higher temperature tolerance than Lepetodrilus fucensis, a member of the family Lepetodrilidae, which includes Clypeosectus delectus and G. spiralis as well as Lepetodrilus species. The three members of the family Neomphalidae that were included in our study (Cyathermia naticoides, Neomphalus fretterae, and Pachydermia laevis) were associated with warmer regions of the vestimentiferan zone or with alvinellids. Although the Warm lepetodrilid species apparently inhabit the alvinellid zone to some degree, our data suggest that they are more commonly found in the vestimentiferan zone temperature range. The Cool lepetodrilid species are typically found at temperatures below $10{ }^{\circ} \mathrm{C}$.

Distinguishing between alternative processes that may influence the distinct distribution of gastropod species requires different strategies than those used in the present study. New techniques for characterizing the physicochemical environment are making sustained measurements feasible on scales approaching those of individual gastropods (Le Bris et al., 2006). Behavioral studies are needed at multiple stages in species' life histories, and under controlled conditions (Lee, 2003; Bates et al., 2005). The gastropods themselves appear to contain a record of their physicochemical environment in the isotopic and elemental composition of their tissues and shell (S. Pendlebury, National Oceanography Centre, University of Southampton, pers. comm.). However, a full understanding of the role of gastropods in the vent ecosystem, and an answer to the question of why we find them in discrete assemblages associated with specific environments, requires that studies be placed in the context of their interactions with other species in the community - prey, predators, competitors, and even potential facilitators.

\section{Acknowledgments}

This work was supported by NSF grants OCE-9712233 (co-PIs Chuck Fisher and Pete Peterson), OCE-9619605 (co-PIs Donal Manahan and Craig Young) and OCE0424953. We thank the captain and crew of the R/V Atlantis II and the R/V Atlantis, the pilots and crew of the submersible DSV Alvin, the chief scientists (Chuck Fisher and Jim Childress) of the cruises on which the blocks were deployed and collected, and members of the science parties who assisted us at sea. Fiorenza Micheli and Nilauro Markus sorted samples from the quantitative block experiments, and
Heather Hunt provided samples from additional blocks for species-level identifications. We appreciate comments on the manuscript by two anonymous reviewers.

\section{Literature Cited}

Bates, A. E., V. Tunnicliffe, and R. W. Lee. 2005. Role of thermal conditions in habitat selection by hydrothermal vent gastropods. Mar. Ecol. Prog. Ser. 305: 1-15.

Chevaldonné, P., C. R. Fisher, J. J. Childress, D. Desbruyères, D. Jollivet, F. Zal, and A. Toulemond. 2000. Thermotolerance and the 'Pompeii worms'. Mar. Ecol. Prog. Ser. 208: 293-295.

Croll, R. P. 1983. Gastropod chemoreception. Biol. Rev. 58: 293-319.

Fustec, A., D. Desbruyères, and K. S. Juniper. 1987. Deep-sea hydrothermal vent communities at $13^{\circ} \mathrm{N}$ on the East Pacific Rise: microdistribution and temporal variations. Biol. Oceanogr. 4(2): 121-164.

Govenar, B., N. Le Bris, S. Gollner, J. Glanville, A. B. Aperghis, S. Hourdez, and C. R. Fisher. 2005. Epifaunal community structure associated with Riftia pachyptila aggregations in chemically different hydrothermal vent habitats. Mar. Ecol. Progr. Ser. 305: 67-77.

Grassle, J. F. 1986. The ecology of deep sea hydrothermal vent communities. Adv. Mar. Biol. 23: 301-362.

Hessler, R. R., and W. M. Smithey, Jr. 1984. The distribution and community structure of megafauna at the Galápagos Rift hydrothermal vents. Pp. 735-770 in Hydrothermal Processes at Seafloor Spreading Centers, P. A. Rona, K. Bostrom, L. Laubier, and K. L. Smith, eds. Plenum Publishing, New York.

Hessler, R. R., W. M. Smithey, Jr., and C. H. Keller. 1985. Spatial and temporal variation of giant clams, tube worms and mussels at deep-sea hydrothermal vents. Bull. Biol. Soc. Wash. 6: 411-428.

Jollivet, D. 1996. Specific and genetic diversity at deep-sea hydrothermal vents: an overview. Biodivers. Conserv. 5: 1619-1653.

Le Bris, N., B. Govenar, C. Le Gall, and C. R. Fisher. 2006. Variability of physico-chemical conditions in $9^{\circ} 50^{\prime} \mathrm{N}$ EPR diffuse flow vent habitats. Mar. Chem. 98: 167-182.

Lee, R. W. 2003. Thermal tolerances of deep-sea hydrothermal vent animals from the Northeast Pacific. Biol. Bull. 205: 98-101.

Luther, G. W., T. F. Rozan, M. Taillefert, D. B. Nuzzio, C. Di Meo, T. M. Shank, R. A. Lutz, and S. C. Cary 2001. Chemical speciation drives hydrothermal vent ecology. Nature 410: 813-816.

McLean, J. H. 1988. New archaeogastropod limpets from hydrothermal vents. Superfamily Lepetodrilacea. Part 1. Systematic descriptions. Philos. Trans. R. Soc. Lond. B 319: 1-32.

McLean, J. H. 1989. New archaeogastropod limpets from hydrothermal vents: new family Peltospiridae, new superfamily Peltospiracea. Zool. Scr. 18: 9-66.

Micheli, F., C. H. Peterson, L. S. Mullineaux, C. R. Fisher, S. W. Mills, G. Sancho, G. A. Johnson, and H. S. Lenihan. 2002. Predation structures communities at deep-sea hydrothermal vents. Ecol. Monogr. 72(3): $365-382$.

Mullineaux, L. S., C. R. Fisher, C. H. Peterson, and S. W. Schaeffer 2000. Tubeworm succession at hydrothermal vents: use of biogenic cues to reduce habitat selection error? Oecologia 123: 275-284.

Mullineaux, L. S., C. H. Peterson, F. Micheli, and S. W. Mills. 2003. Successional mechanism varies along a gradient in hydrothermal fluid flux at deep-sea vents. Ecol. Monogr. 73(4): 523-542.

Sancho G., C. R. Fisher, S. Mills, F. Micheli, G. A. Johnson, H. S. Lenihan, C. H. Peterson, and L. S. Mullineaux. 2005. Selective predation by the zoarcid fish Thermarces cerberus at hydrothermal vents. Deep-Sea Res. 152: 837-844.

Sarrazin, J., and S. K. Juniper. 1999. Biological characteristics of a hydrothermal edifice mosaic community. Mar. Ecol. Prog. Ser. 185: $1-19$.

Sarrazin, J., K. S. Juniper, G. Massoth, and P. Legendre. 1999. Phys- 
ical and chemical factors influencing species distributions on hydrothermal sulfide edifices of the Juan de Fuca Ridge, northeast Pacific. Mar. Ecol. Prog. Ser. 190: 89-112.

Shank, T., D. J. Fornari, K. L. von Damm, M. D. Lilley, R. M. Haymon, and R. A. Lutz. 1998. Temporal and spatial patterns of biological community development at nascent deep-sea hydrothermal vents ( $9^{\circ} 50^{\prime}$ N, East Pacific Rise). Deep-Sea Res. Part II 45: 465-516.

Van Dover, C. L. 2003. Variation in community structure within hydrothermal vent mussel beds of the East Pacific Rise. Mar. Ecol. Prog. Ser. 253: 55-66. von Damm, K. L. 1995. Controls on the chemistry and temporal variability of seafloor hydrothermal fluids. Pp. 222-247 in Seafloor Hydrothermal Systems: Physical, Chemical, Biological, and Geological Interactions, S. E. Humphris, R. A. Zierenberg, L. S. Mullineaux, and R. E. Thomson, eds. American Geophysical Union, Washington, DC.

Warén, A., and P. Bouchet. 1989. New gastropods from East Pacific hydrothermal vents. Zool. Scr. 18: 67-102.

Warén, A., and P. Bouchet. 1993. New records, species, genera, and a new family of gastropods from hydrothermal vents and hydrocarbon seeps. Zool. Scr. 22: 1-90. 